\title{
AVALIAÇÃO DA QUALIDADE ESPACIAL E AMBIENTAL DE EDIFÍCIOS DE APARTAMENTOS EM CIDADES MÉDIAS: ANÁLISE DO PROCESSO PROJETUAL EM CONSTRUTORAS DE UBERLÂNDIA-MG E RIBEIRÃO PRETO- SP
}

\author{
Elza Cristina Santos \\ Faculdade de Arquitetura e Urbanismo e Design - Universidade Federal de Uberlândia \\ elzacristina@hotmail.com

\begin{abstract}
Alessandra Pantaleão Dirscherl Graduanda em Arquitetura e Urbanismo - Universidade Federal de Uberlândia alepantadir@hotmail.com
\end{abstract}

\section{Resumo}

Com a forte urbanização e consequente verticalização das cidades médias, principalmente e partir do ano de 2003, o setor imobiliário começou a atribuir mais importância à imagem veiculada através das propagandas de edifícios residenciais do que com as necessidades dos usuários que viriam morar nesses edifícios. Há uma discussão sobre a importância do processo projetual, incluindo aspectos sustentáveis, na evolução dos projetos de habitação vertical, já que esse processo retroalimenta projetos futuros. Este artigo pretende exibir qual é a preocupação das incorporadoras e construtoras responsáveis por projetar habitações verticais em cidades médias no que diz respeito ao processo de projeto de arquitetura e aos aspectos sustentáveis em uma construção. Para isso, foi realizada uma pesquisa teórica sobre os assuntos mencionados e elaborado um questionário, utilizado em entrevistas com construtoras e incorporadoras da cidade de Uberlândia-MG e Ribeirão Preto-SP. Por fim os resultados das entrevistas foram comparados a fim de se verificar quais aspectos foram mais importantes em cada cidade.

Palavras-chave: Processo projetual. Sustentabilidade. Habitação vertical.

\section{EVALUATION OF THE SPATIAL AND ENVIRONMENTAL QUALITY OF APARTMENT BUILDINGS IN MEDIUM CITIES: ANALYSIS OF THE DESIGN PROCESS IN BUILDERS OF UBERLÂNDIA-MG AND RIBEIRÃO PRETO-SP}

\begin{abstract}
As a result of the urbanization and verticalization in medium sized cities, mainly from the year 2003, the real estate department has begun to attribute more importance to the image viewed through publicity about buildings instead of concerning about the needs of the people whom would live in these places. There is a discussion about the importance of the design process, including sustainable aspects, in the evolution of vertical housing projects, since these process feedbacks future projects. This article intends to exhibit what is the concern of the developers and companies that builds vertical houses in medium sizes cities according to
\end{abstract}


the design process and sustainable aspects in a construction. So, it was made a theoretical research about the issues already mentioned and it was structured a questionnaire, which was used in an interview with developers and companies that builds vertical houses in the cities of Uberlândia-MG and Ribeirão Preto-SP. At last, the results of the interviews were compared in order to find out what aspects are more important in each city.

Keywords: Design process. Sustainability. Vertical housing.

\section{Introdução}

Há um interesse cada vez maior, tanto dos cidadãos quanto das empresas, no que diz respeito à sustentabilidade ambiental, sendo necessário que os aspectos sociais, econômicos e culturais sejam levados em consideração. De acordo com Lambertset et al. (1997), com a crise energética em 1970, o Brasil começou a valorizar a produção de eletricidade, por isso este setor passou por um rápido crescimento; mas juntamente a isto ocorreram muitos impactos negativos ambientais e sociais, assim, houve uma grande preocupação com a sustentabilidade, incluindo o segmento da construção civil.

Com o crescimento urbano, as habitações foram se verticalizando e a partir do ano de 2003 o setor imobiliário começou a difundir os imóveis com grande apelo na área publicitária, deixando as necessidades dos usuários como algo superficial. $\mathrm{O}$ processo do projeto arquitetônico, entretanto, deve buscar a qualidade de vida dos moradores, priorizando as questões sustentáveis ecologicamente. A maior compreensão dos valores humanos e o reconhecimento do comportamento sócio-espacial humano são elementos fundamentais para elaboração de propostas com nítidas implicações sócio-ambientais.

Bertezini (2006) faz uma discussão ainda mais profunda sobre o processo do projeto arquitetônico, ressaltando a organização de informação e avaliações das próprias empresas do projeto. Elali e Veloso (2006) defendem que esses processos são importantes para a melhora do repertório do arquiteto.

Por isso, é importante na formação do arquiteto saber avaliar edificações a fim de se melhorar um projeto futuro e corrigir o que foi feito de forma equívoca nos projetos anteriores. As certificações da construção civil e a etiquetagem ajudam na comparação de edifícios, tanto no aspecto sustentável quanto social e econômica.

Foram escolhidas, nas cidades de Uberlândia - MG e de Ribeirão Preto - SP, incorporadoras e construtoras para a realização de entrevistas a fim de indagar sobre o processo projetual. Para isso elaborou-se um questionário, baseado em questões sobre o 
Elza Cristina Santos; Alessandra Pantaleão Dirscherl

mercado imobiliário atual e sobre a importância do processo projetual, no que diz respeito à qualidade espacial e ambiental, à sustentabilidade e ainda sobre a importância das certificações de qualidade habitacional nos dias atuais.

Com o processo de documentação dessas entrevistas foi possível analisar alguns aspectos do processo de projeto de arquitetura, bem como verificar aspectos da habitação vertical produzida hoje, questões importantes para a alimentação de outros projetos futuros.

Para a elaboração do questionário foram considerados aspectos relacionados à qualidade das habitações, sendo necessário, portanto, desenvolver uma pesquisa teórica sobre o processo de projeto de arquitetura, a sustentabilidade e as certificações.

\section{Objetivo}

O presente artigo descreve uma etapa de um projeto maior de avaliação da qualidade espacial e ambiental, englobando estratégias de sustentabilidade, de edifícios de apartamentos projetados a partir do ano de 2000 por construtoras de Uberlândia-MG e Ribeirão Preto-SP para atender a demanda da classe média dessas cidades, na qual foram identificadas e analisadas as etapas do processo projetual de empreendimentos de edifícios nas cidades citadas, bem como as estratégias de sustentabilidade utilizadas por parte das construtoras, e ainda; uma pesquisa sobre as certificações existentes na construção civil. Essas pesquisas tiveram como objetivo a elaboração de um questionário a fim de se perceber qual é a importância do processo projetual de arquitetura para as construtoras.

\section{Metodologia}

Primeiramente, foi feita uma avaliação sobre o processo projetual e suas etapas, bem como uma identificação dos principais agentes imobiliários envolvidos nos projetos de empreendimentos imobiliários para a classe média nas cidades de Uberlândia-MG e Ribeirão Preto-SP. Para complementação do estudo do processo projetual foi realizada uma pesquisa sobre as estratégias de sustentabilidade utilizadas em projetos arquitetônicos, e também foram identificadas as principais certificações na qualidade na construção civil. Sendo assim, foi possível estruturar um questionário, que foi utilizado para entrevistas com construtoras das duas cidades citadas anteriormente. Tais entrevistas foram comparadas, obtendo-se um relatório de comparação com os dados conseguidos nelas. 
Elza Cristina Santos; Alessandra Pantaleão Dirscherl

\section{O Processo Projetual}

O projeto arquitetônico é importante por permitir a resolução de questões relativas aos aspectos construtivos e espaciais, atender um programa de necessidades que seja adequado ao pedido do cliente, detalhar produtos e alcançar uma solução que possua a qualidade esperada.

O projeto arquitetônico trata-se da concepção espacial do que será construído até a sua construção total. O projeto deve reduzir alguns problemas que possam acontecer durante a fase de construção, também faz com que o tempo de realização da obra seja menor e que seja cumprida no tempo estipulado, mas que ocorra com qualidade e funcionalidade, sem gastos extras.

Para que a fase de construção seja executada com tal eficiência é válido considerar a existência de um banco de dados que registre esses processos de projeto e de construção, a fim de que se tornem mais eficazes e com uma menor escala de erros.

É importante que os arquitetos possuam uma visão interdisciplinar, pois devem ser capazes de atender um cliente de acordo com suas vontades e necessidades, conhecer técnicas construtivas e materiais diversos, combinar em seu projeto a estética (forma) e a função que deverá ser atendida, criar um produto condizente com a realidade e compreender sua própria cultura. (SALGADO, 2004).

A primeira providência que se toma quando se projeta é criar um programa de necessidades de acordo com o que o cliente deseja. Esse programa deve ser adequado para suprir as condições que o cliente explicitou.

É necessário ressaltar que o programa não limita a criatividade do arquiteto, são diretrizes para que a satisfação do cliente possa ser alcançada, mas não impede o ímpeto criativo. Além disso, é importante que o profissional saiba "passar para o desenho", ou seja, a apresentação de seu trabalho deve conter as informações de forma clara para que o cliente entenda o projeto. Esse programa de necessidades deve passar por revisões até mesmo durante a fase de processo de projeto.

No caso estudado, em que o cliente é uma construtora, em que o arquiteto trabalha ou que foi contratado por ela, os projetos atendem ao que a construtora pede, e em alguns casos, o que o próprio cliente da construtora deseja. (SALGADO, 2004).

O Manual de Escopo de Serviços para a Coordenação de Projetos da AGESC (Agência Reguladora de Serviços Públicos de Santa Catarina) define as fases do processo de projeto em seis: concepção do produto, definição do produto, identificação e solução de interfaces de 
Elza Cristina Santos; Alessandra Pantaleão Dirscherl

projeto, detalhamento de projetos, pós-entrega de projetos, e pós-entrega da obra (SANTANA, 2009). Todas as fases são resumidamente explicadas a seguir na tabela 1.

Tabela 1 - Fases do projeto

\begin{tabular}{|c|c|}
\hline FASE & OBJETIVO \\
\hline A - Concepção do produto & $\begin{array}{l}\text { Levantar informaçoes jurídicas, legais, programáticas e técnicas; } \\
\text { dados analiticos e gráficos; } \\
\text { Determinar as restriçoes e possibilidades que regem e limitam o } \\
\text { produto imobiliário pretendido. } \\
\text { Caracterizar o partido e as possiveis soluçoes das edificaçoes e de } \\
\text { implantaçao dentro das condicionantes levantadas. }\end{array}$ \\
\hline B - Definiçāo do produto & $\begin{array}{l}\text { Deservolver o partido arquitetônico e demais elementos; } \\
\text { Definir e consolidar todas as informaçoes necessárias a fim de } \\
\text { verificar sua viabilidade fisica, legal e econômica, e possibilitar a } \\
\text { elaboraçao dos Projetos Legais. }\end{array}$ \\
\hline $\begin{array}{l}\text { C - Identificação e solução } \\
\text { de interfaces de projeto }\end{array}$ & $\begin{array}{l}\text { Consolidar todos ambientes, articulaçoes e demais elementos do } \\
\text { empreendimento, com as definiçoes necessárias para o intercâmbio } \\
\text { entre todos envolvidos no processo. } \\
\text { O projeto resultante deve ter todas as suas interfaces resolvidas, } \\
\text { possibilitando uma avaliaçao preliminar dos custos, métodos } \\
\text { construtivos e prazos de execuçao. }\end{array}$ \\
\hline $\begin{array}{l}\text { D - Detalhamento de } \\
\text { projetos }\end{array}$ & $\begin{array}{l}\text { Executar o detalhamento de todos os elementos do empreendimento } \\
\text { e incorporar os detalhes necessários de produçao dependendo do } \\
\text { sistema construtivo; } \\
\text { Gerar um conjunto de referências para a perfeita caracterizaçao das } \\
\text { obras/serviços, a avaliaçao dos custos, métodos construtivos e } \\
\text { prazos de execuçao. } \\
\text { O resultado deve ser um conjunto de informaçoes técnicas claras e } \\
\text { objetivas sobre todos os elementos, sistemas e componentes do } \\
\text { empreendimento. }\end{array}$ \\
\hline E-Pós-entrega de projetos & $\begin{array}{l}\text { Garantir a plena compreensao e utilizaçao das informaçoes de } \\
\text { projeto, e sua aplicaçao correta nos trabalhos de campo. }\end{array}$ \\
\hline F - Pós-entrega da obra & $\begin{array}{l}\text { Analisar e avaliar o comportamento da edificaçao em uso para } \\
\text { verificar e reafirmar se os projetos foram adequados e se eventuais } \\
\text { alteraçoes, realizadas em obra, estao compativeis com as } \\
\text { expectativas do empreendedor e de ocupaçao dos usuários. }\end{array}$ \\
\hline
\end{tabular}

Fonte: SANTANA, 2009

Dentre os agentes necessários para que o processo de projeto seja realizado é importante citar: os proprietários, os clientes, as imobiliárias, as construtoras, as incorporadoras e os arquitetos. Cada agente possui uma função, os proprietários e clientes são importantes porque são eles que fazem com que o mercado exista, as imobiliárias tem o papel de divulgar, intermediar aluguéis e compras. As construtoras são importantes para projetar e construir o edifício, e as incorporadoras para que a construção seja possível de ser realizada. Os arquitetos projetam edificações de acordo com o pedido de clientes de maneira tanto funcional quanto estética, de modo que as necessidades de quem os contratam sejam supridas.

É importante que as construtoras saibam quais são as etapas do processo de projeto, para ter um maior controle no projeto e na construção, pois é por meio do projeto que é possível saber o custo, funcionalidade e tecnologias de construção (CAIADO, 2004). 
Elza Cristina Santos; Alessandra Pantaleão Dirscherl

Cabe aqui, ressaltar a importância de um gerente e um coordenador de projetos. O gerente toma decisões estratégicas, tem a responsabilidade de controlar e também planejar a execução de projetos arquitetônicos para que o propósito do mesmo seja alcançado. Já o coordenador de projetos possui a responsabilidade de organizar o cronograma das atividades que serão realizadas, estipulando sua programação. Assim, define pelo que cada profissional será responsável e define alguns dos custos da construção.

O empreendedor é o responsável pela iniciação de um processo de projeto, por isso é de muita importância sua participação no mesmo. Às vezes ocorre um distanciamento entre esse e o projeto, que pode ser explicado pela falta de interesse do empreendedor ou pelo desconhecimento das etapas do processo, até mesmo por ignorar que seja importante sua presença no processo (ADESSE; SALGADO, 2006).

As empresas de arquitetura e as construtoras devem estabelecer as etapas de projeto, para que esse seja bem gerenciado, assim entra a importância de se ter um gerente de projetos, que muitas vezes é dispensado porque alguns empreendedores estão somente interessados no retorno financeiro dos projetos, não possuindo uma visão de que um gerente de projetos pode minimizar custos e aumentar a qualidade das construções, aumentando, como consequência, os lucros da empresa.

A partir do século XXI muitos profissionais da construção civil procuraram padronizar o processo de projeto, a fim de melhorar e facilitar a gestão da qualidade de projetos, porém muitos arquitetos não aprovam essa ideia, uma vez que pode limitar a criação.

Em razão da alta demanda por habitações, conhecido como "boom" da construção civil (VILLA, CAETANO, 2013), várias construtoras e incorporadoras passaram por uma dificuldade em encontrar mão de obra que fosse qualificada, por isso, muitos empreendimentos possuem uma qualidade inferior àquela que se deveria ter.

Foi a partir de 2000 que surgiu o desenvolvimento de uma norma técnica como consequência da má qualidade das habitações que estavam sendo construídas. Assim, essa norma definiu parâmetros de um mínimo desempenho no ambiente construído, é a ABNT NBR 15.575.

As exigências básicas da norma são: desempenho estrutural; segurança contra incêndio, uso e operação; estanqueidade; desempenho térmico, acústico e lumínico; durabilidade e manutenibilidade; saúde, higiene e qualidade do ar; funcionalidade e acessibilidade; conforto 
Elza Cristina Santos; Alessandra Pantaleão Dirscherl

tátil e antropodinâmico e adequação ambiental (VILLA, CAETANO, 2013). A tabela 2 mostra essas exigências, seguidos de uma pequena definição.

O principal papel da norma é regularizar projetos para que as construções sejam melhores executadas e projetadas, visando sua qualidade. Com isso, também diminui a probabilidade do consumidor ser prejudicado, evitando a compra de um imóvel sem qualidade.

Além da norma é necessário que haja uma boa fiscalização no país, hábito que ainda está em desenvolvimento. Se a fiscalização for falha, isso pode refletir na credibilidade da norma.

Como a norma foi implantada somente recentemente, é necessário que esteja em constante aperfeiçoamento, pois os problemas aparecerão através da prática.

É fundamental coletar dados e medir resultados da aplicação do projeto em obra para analisá-los, objetivando uma melhor compreensão do impacto das decisões tomadas em projeto. Ao final, ficam documentadas as boas soluções e também as más, evitando-se repetir os erros anteriormente cometidos pelos projetistas. Essa sistemática, além de subsidiar a evolução dos procedimentos da empresa, serve como banco de informações para a elaboração e coordenação de projetos futuros, agindo também como ferramenta para aumentar a competitividade da construtora. (SOUZA, MELHADO, 1998). 


\section{Elza Cristina Santos; Alessandra Pantaleão Dirscherl}

Tabela 2: Exigências da NBR 15.575

\begin{tabular}{|c|c|c|}
\hline $\begin{array}{l}\text { Desempenho } \\
\text { Estrutural }\end{array}$ & & $\begin{array}{l}0 \text { projeto deve prever que os estados limites de serviço não causem prejuizos a outros elementos } \\
\text { de construção. } 0 \text { manual do proprietário deve conter informaçöes acerca de sobrecargas. }\end{array}$ \\
\hline $\begin{array}{l}\text { Segurança } \\
\text { Contra Incêndio }\end{array}$ & & $\begin{array}{l}\text { Os conceitos se dirigem para a baixa probabilidade de incêndio, alta probabilidade de os usuários } \\
\text { sobreviverem sem sofrer qual quer tipo de injúria, e reduzida extensão de danos à propriedade } \\
\text { eà vizinhança imediata ao local de origem do incéndio. A maior parte dos critérios segue } \\
\text { normas prescritivas já existentes, e os métodos de avaliação, em sua maioria, baseiam-se } \\
\text { em análises de projeto. }\end{array}$ \\
\hline $\begin{array}{l}\text { Segurança no } \\
\text { Uso e na Operaçảo }\end{array}$ & & $\begin{array}{l}\text { 0s sistemas nâo devem apresentar rupturas, instabilizaçōes, partes cortantes ou perfurantes, } \\
\text { deformaçöes ou defeitos acima dos limites especificados nas demais partes da Norma. Sobre } \\
\text { segurança das instalaçôes, deve-se evitar a ocorrência de ferimentos aos usuários, atendendo-se } \\
\text { às normas prescritas pertinentes. }\end{array}$ \\
\hline Estanqueidade & & $\begin{array}{l}\text { Os requisitos e métodos de avaliação estão especificados em cada parte pertinente da Norma. } \\
\text { Fontes de umidade externa, por exemplo, aparecern nas partes de Pisos Internos, Vedaçōes e } \\
\text { Coberturas. Sobre fontes de umidade internas à edificaçáo, a Norma determina que devem ser } \\
\text { verificados em projeto os detalhes pertinentes que assegurem a estanqueidade, como as } \\
\text { vinculaçóes entre instalaçôes de água, esgoto e caixas d'água com estrutura, pisos e paredes. }\end{array}$ \\
\hline $\begin{array}{l}\text { Desempenho } \\
\text { Térmico }\end{array}$ & & $\begin{array}{l}\text { Ambientes de permanência prolongada (sala, dor mitório) devem apresentar condiçōes melhores } \\
\text { que a externa, ou seja, temperatura igual ou inferior à externa, no verão. }\end{array}$ \\
\hline $\begin{array}{l}\text { Desempenho } \\
\text { Acústico }\end{array}$ & & $\begin{array}{l}\text { Os limites sonoros e o método de avaliaçăo de fontes externas de ruido șáo apontados em norma } \\
\text { correspondente (NBR 10.152). Sobre isolaçáo acústica entre ambientes internos, cada parte da } \\
\text { norma especifica os critérios e métodos de avaliaçâo para cada sistema. }\end{array}$ \\
\hline $\begin{array}{l}\text { Desempenho } \\
\text { Lumínico }\end{array}$ & & $\begin{array}{l}\text { A Norma trata tanto da iluminação natural como da artificial. O iluminamento geral mínimo para } \\
\text { luz natural deve ser de pelo menos } 60 \text { lux, e, para luz artificial, pelo menos } 100 \text { lux ou } 50 \text { lux em } \\
\text { corredores, escadarias e garagens. }\end{array}$ \\
\hline $\begin{array}{l}\text { Durabilidade e } \\
\text { Manutenibilidade }\end{array}$ & & $\begin{array}{l}\text { A Norma indica os prazos de Vida Útil de Projeto (VUP) e orienta para os prazos de garantia. Um } \\
\text { mesmo sisterna (ou elemento, componente, instalaçäo) tem prazos de garantia variados quanto a } \\
\text { ocorréncias diferentes. Para revestimentos de paredes, por exemplo, a garantia indicada é de trés } \\
\text { anos para estanqueidade das fachadas e dois anos para ocorrência de fissuras. }\end{array}$ \\
\hline $\begin{array}{l}\text { Saúde, Higiene } \\
\text { e Qualidade do Ar }\end{array}$ & & $\begin{array}{l}\text { As exigências de salubridade sâo estabelecidas por regulamentos daAnvisa (Agência Nacional de } \\
\text { Vigiláncia Sanitária). No geral, deve-se evitar a proliferaçăo de micro-organismos e limitar os } \\
\text { poluentes na atmosfera interna de acordo com normas e resoluçôes daAnvisa. }\end{array}$ \\
\hline $\begin{array}{l}\text { Funcionabilidade } \\
\text { eAcessibilidade }\end{array}$ & & $\begin{array}{l}\text { A Norma define as medidas minimas de mobiliário e espaço de circulaçāo. Sobre adequação a } \\
\text { portadores de deficiência, a Norma enuncia que deve-se seguir os critérios da ABNT NBR } 9.050 \text {. No } \\
\text { caso de ampliaçăo da unidade habitacional, o incorporador ou o construtor deve incluir no lilanual de } \\
\text { Uso e Manutençáo do usuário as detalhes construtivos necessárias, de forma que a construção } \\
\text { ampliada mantenha pelo menos os mesmos niveis de desempenho que a construção original. }\end{array}$ \\
\hline $\begin{array}{l}\text { Conforto Tátil e } \\
\text { Antropodinàmico }\end{array}$ & & $\begin{array}{l}\text { As partes da edificação não devem apresentar rugosidades, contundências ou outras } \\
\text { irregularidades que possam prejudicar o caminhar, apoiar, limpar, brincar e demais atividades } \\
\text { normais, Quanto a dispositivos de manobra, como portas, janelas, torneiras, a força necessária } \\
\text { para seu acionamento não deve exceder } 10 \mathrm{~N} \text { e seu torque não deve exceder } 20 \mathrm{Nm} \text {. }\end{array}$ \\
\hline $\begin{array}{l}\text { Adequaçảo } \\
\text { Ambiental }\end{array}$ & & $\begin{array}{l}\text { De forma geral, os empreendimentos devem ser projetados e construídos visando a minimo de } \\
\text { interferência no meio. Devem ser considerados riscos de desconfinamento do solo, enchentes, } \\
\text { erosêo, entre outros. Deve-se privilegiar a utilizaçấo de materiais que causem menor impacto } \\
\text { ambiental, madeiras certificadas, implementar sistema de gestão de residuos, possibilitar o reúso da } \\
\text { água, minimizar o consumo de energia, entre outras recomendaçöes. }\end{array}$ \\
\hline
\end{tabular}

Fonte: VILLA, CAETANO (2013). 
Elza Cristina Santos; Alessandra Pantaleão Dirscherl

Há pesquisas centradas em avaliar a qualidade de habitação depois que são ocupadas, são as chamadas avaliações pós - ocupação. Possuem como objetivo analisar como o modo da pessoa morar influencia no seu modo de vida. É através da APO (avaliação pós ocupação) que percebe-se se a qualidade do projeto é satisfatória para os moradores. A escassez das APOs faz com que seja mais difícil que os projetos sejam retroalimentados, uma vez que a avaliação é importante para melhorar projetos futuros. (VILLA, 2009).

Essas avaliações são feitas a partir de questionários com os moradores, que são indagados sobre qualidade espacial, funcional, estética e sobre a materialidade de onde vivem. Há também uma dinâmica chamada "grupo focal" onde são feitas algumas atividades e os moradores falam sobre suas moradias, as qualidades e os defeitos.

\section{Sustentabilidade}

A sustentabilidade visa a exploração dos recursos naturais de forma inteligente, de modo a suprir as necessidades das atividades humanas atualmente sem que as gerações futuras sejam comprometidas. Para que isso ocorra é necessário pensar na sustentabilidade como um todo, levando em consideração os indicadores ambientais, sociais (refere a uma sociedade justa com oportunidade para todos) e econômicos (busca alternativa para que as pessoas tenham acesso aos recursos de forma mais igualitária).

Segundo a ONU, o desenvolvimento sustentável é "aquele que atende as necessidades do presente sem comprometer a possibilidade de as gerações futuras atenderem as suas próprias necessidades".

A construção civil gera muito lixo, pois a maioria dos materiais é descartada sem serem reutilizados e, na maioria das vezes não são possíveis de serem reciclados. Hoje em dia, porém a reciclagem e a sustentabilidade ambiental são muito discutidas. Por isso é importante que se saiba usar os materiais e tecnologias que visam interferir ao mínimo no ambiente e os impactos negativos que a ele causará (MARQUES, SALGADO, 2007).

Para que se entenda melhor sobre os aspectos de sustentabilidade social, econômico e ambiental pode-se observar na tabela abaixo, contendo de forma reduzida, os aspectos que são essenciais para reduzir o impacto de uma edificação. Cada obra deve se adequar às características que melhor condiz com a finalidade da proposta. 
Elza Cristina Santos; Alessandra Pantaleão Dirscherl

Tabela 3: Indicadores de sustentabilidade

\begin{tabular}{|l|l|}
\hline \multicolumn{2}{|l|}{ Indicadores de sustentabilidade } \\
\hline Indicadores ambientais & Uso de matérias-primas naturais \\
& Consumo de energia \\
& Liberação de emissões danosas ao ambiente \\
\hline Indicadores sociais & Acessibilidade (transporte público, ciclistas, pedestres) \\
& Vida útil \\
& Ambiente interno \\
& Uso sem barreiras (barrier-free) \\
\hline Indicadores econômicos & Custos ao longo do ciclo de vida \\
\hline
\end{tabular}

Fonte: SILVA (2007).

Com o crescente aumento dos impactos no ambiente, se tornou de grande importância, no ramo da arquitetura, projetar tipologias com interesse e preocupação na sustentabilidade. As ações de sustentabilidade devem levar em consideração o ciclo de vida do edifício, o custo de operação, o uso e a manutenção ao longo do tempo, e não somente na fase inicial, considerando apenas o custo inicial. A utilização de materiais que diminuam o impacto ambiental também é de extrema importância, pois o lixo que é gerado na construção de uma obra é dificilmente reciclado, apesar de nos dias atuais isso estar mudando. Por isso, a reciclagem e reutilização da construção civil é um meio sustentável muito válido.

As estratégias sustentáveis tendem a diminuir o impacto causado pelo uso em grande quantidade dos recursos naturais, bem como diminuir o consumo de energia e de água, podendo utilizar recursos que a água de certo local possa ser reutilizada para outras tarefas na mesma residência ou edificação.

Há várias maneiras de reduzir o consumo de energia e de água. Primeiramente a implantação do edifício no terreno, isso depende do local que a construção vai se concretizar, mas se orientado de maneira correta, pode reduzir gastos com ar condicionado, e até mesmo aquecedores, dependendo do país. As aberturas também são importantes para reduzir o gasto da energia utilizada para iluminar o ambiente, além disso, quando bem orientadas favorecem a ventilação. Quando não é possível orientar um cômodo para a melhor fachada é importante utilizar proteções solares, a exemplo do brise-soleil, muito utilizado no Brasil.

No que diz respeito à utilização da água, é preciso que a população se conscientize para reduzir desperdícios, por exemplo, durante o banho, escovando os dentes, ou diminuir o tempo em uma lavagem de carro ou calçadas, e também que os estabelecimentos tenham algum tipo de recurso de reutilização da água. Em muitos lugares há um coletor de água 
Elza Cristina Santos; Alessandra Pantaleão Dirscherl

pluvial, que encaminha a mesma até um reservatório, essa água é utilizada para aguar jardins e lavar quintais.

O entulho produzido pela construção civil é grande. Para a redução dos resíduos da construção é interessante adotar o emprego de materiais reciclados, materiais que possuem vida útil longa, e que após seu uso possam ser reciclados. Outra alternativa é a reciclagem dos entulhos, um recurso que já está sendo muito utilizado.

É importante que os profissionais dessa área, não somente arquitetos, mas também engenheiros, mestre de obras, entre outros, comecem a projetar e a construir de maneira que visem a sustentabilidade. No Brasil, é cada vez mais comum observar a preocupação com a sustentabilidade na construção civil, podendo ser aplicado através dos materiais escolhidos (MARQUES, SALGADO, 2007).

O primeiro passo para começar a projetar de maneira sustentável é saber o objetivo do cliente, e estabelecer uma relação de importância entre ele e o projeto. É na fase de processo de projeto que os aspectos de sustentabilidade da construção, do uso e manutenção do edifício são analisados e avaliados perante os objetivos do cliente (LIMA, 2009).

O LEED (Leadership in Energy and Environmental Design), processo de certificação ambiental, possui pré-requisitos para a avaliação de acordo com parâmetros americanos. Sendo, assim, observando a tabela 4 é possível concluir que os aspectos de sustentabilidade devem ser pensados durante a fase de processo do projeto, sendo possível reduzir os impactos ambientais, sociais e econômicos. Assim, é possível mudar aspectos visíveis que não condizem com a realidade do lugar ou que não sejam sustentáveis.

Essas alternativas sustentáveis devem ser pensadas no momento de idealização e concepção do projeto, ou seja, para que já tenha definido quais medidas serão usadas na sua fase de projeto e construção. Só assim é possível ter uma visão mais geral do que o projeto vai necessitar, sendo que se as propostas forem somente solucionadas na fase de construção podem ocorrer imprevistos e erros. É importante ressaltar que os aspectos sustentáveis devem ser inseridos em todas as fases do projeto, desde a concepção até a construção.

A maioria das incorporadoras não se preocupa em implantar estratégias de sustentabilidade em seus edifícios, porém, a exigência nesse requisito está aumentando. Mesmo assim, muitos responsáveis pelas obras pensam nisso somente na etapa de realização da construção, sendo que é necessário que as estratégias sejam analisadas e previstas na primeira fase do projeto, a fase de concepção. 
A sustentabilidade de uma edificação é algo complexo, não se resume às decisões e dispositivos técnicos somados ao projeto. Depende de uma abordagem bastante ampla dos problemas ambientais, econômicos e sociais pertinentes, bem como depende de um compromisso ético ambiental e social de todos os atores envolvidos ao longo de todo o processo de um empreendimento. (ZAMBRANO, 2008).

Tabela 4: Aspectos sustentáveis

\begin{tabular}{|c|c|c|}
\hline $\begin{array}{l}\text { Localizaçao do } \\
\text { empreendimento }\end{array}$ & $\begin{array}{l}\text { Pré-requisito 1- } \\
\text { Controle da } \\
\text { erosao e } \\
\text { sedimentaçáo }\end{array}$ & $\begin{array}{l}\text { Credito } 1 \text { - Escolha do sitio } \\
\text { Credito } 2 \text { - Grau de desenvolvimento } \\
\text { Credito } 3 \text { - Recuperaçao de áreas danificadas } \\
\text { Credito } 4 \text { - Transporte alternativo } \\
\text { Credito } 5 \text { - Reduçao de impactos ambientais } \\
\text { Credito } 6 \text { - Gestao das áquas das chuvas } \\
\text { Credito } 7 \text { - Reduçao das ilhas de calor } \\
\text { Credito } 8 \text { - Reduçao da poluiçao visual }\end{array}$ \\
\hline $\begin{array}{l}\text { Gestâo do uso da } \\
\text { água: }\end{array}$ & \multicolumn{2}{|c|}{$\begin{array}{l}\text { - Credito } 1 \text { - Uso eficiente da água } \\
\text { - Credito } 2 \text { - reduçao no desperdício de água } \\
\text { Credito } 3 \text { - reduçáo no uso da água }\end{array}$} \\
\hline \multirow{3}{*}{$\begin{array}{l}\text { Conservaçao da } \\
\text { energia e } \\
\text { preservaçao da } \\
\text { atmosfera }\end{array}$} & \multicolumn{2}{|c|}{ Pré-requisito 1 -Funcionamento dos sistemas prediais } \\
\hline & \multicolumn{2}{|c|}{$\begin{array}{l}\text { Pré-requisito } 2 \text { - Maximizaçao da eficiência dos sistemas artificiais (que demandam } \\
\text { utilizaçao de energia) }\end{array}$} \\
\hline & $\begin{array}{l}\text { Pré-requisito } 3 \text { - } \\
\text { Reduçáo } \\
\text { emissoes de CFC }\end{array}$ & $\begin{array}{l}\text { Credito } 1 \text { - Otimização do desempenho energético } \\
\text { Credito } 2 \text { - Utilizaçăo de Energia renovável } \\
\text { Credito } 3 \text { - Definiçao de uma Comissao de Verificaçao } \\
\text { Credito } 4 \text { - Preservaçăo da Camada de Ozônio } \\
\text { Credito } 5 \text { - Monitoramento } \\
\text { Credito } 6 \text { - "Poder Verde" (Green power) }\end{array}$ \\
\hline $\begin{array}{l}\text { Materiais e } \\
\text { Recursos }\end{array}$ & $\begin{array}{l}\text { Pré-requisito } 1{ }^{1}- \\
\text { Armazenamento de } \\
\text { recicláveis }\end{array}$ & $\begin{array}{l}\text { Credito } 1 \text { - Reutilizaçao de edificaçoes existentes } \\
\text { Credito } 2 \text { - Gerenciamento do entulho da obra } \\
\text { Credito } 3 \text { - Reaproveitamento de recursos } \\
\text { Credito } 4 \text { - Reciclagem } \\
\text { Credito } 5 \text { - Adoçao de materiais locais } \\
\text { Credito } 6 \text { - Utilizaçăo de materiais de fácil obtençao } \\
\text { Credito } 7 \text { - Madeira certificada }\end{array}$ \\
\hline \multirow{2}{*}{$\begin{array}{l}\text { Qualidade do } \\
\text { ambiente interno }\end{array}$} & \multicolumn{2}{|c|}{ Pré-requisito 1 - Desempenho satisfatório do LAQ } \\
\hline & $\begin{array}{l}\text { Pré-requisito } 2 \text { - } \\
\text { Controle ambiental } \\
\text { da fumaça do cigarro }\end{array}$ & $\begin{array}{l}\text { Credito } 1 \text { - Dióxido de carbono } \\
\text { Credito } 2 \text { - Ventilaçao eficaz } \\
\text { Credito } 3 \text { - Definiçáo de um plano de garantia da qualidade } \\
\text { do ar interior } \\
\text { Credito } 4 \text { - Pureza do ar } \\
\text { Credito } 5 \text { - Controle dos poluentes } \\
\text { Credito } 6 \text { - Controle dos sistemas } \\
\text { Credito } 7 \text { - Conforto térmico } \\
\text { Credito } 8 \text { - lluminaçáo natural e conforto visual }\end{array}$ \\
\hline $\begin{array}{l}\text { Soluçoes } \\
\text { Inovadoras }\end{array}$ & \multicolumn{2}{|c|}{$\begin{array}{l}\text { Credito } 1 \text { - Inovaços no projeto } \\
\text { Credito } 2 \text { - LEED }{ }^{M M} \text { acreditaçao profissional }\end{array}$} \\
\hline
\end{tabular}

Fonte: MARQUES, SALGADO, 2007

Hoje existe uma etiquetagem, como feito em eletrodomésticos, para as residências que consomem pouca energia. Esse processo foi elaborado pela Eletrobrás e pelo Instituto Nacional de Metrologia, Normalização e Qualidade Industrial, o Inmetro. 
Elza Cristina Santos; Alessandra Pantaleão Dirscherl

A etiquetagem nacional é concedida pelo Programa Brasileiro de Etiquetagem (PBE), avaliando os aspectos de energia elétrica, assim como o desempenho das fachadas, coberturas e materiais, também aspectos de iluminação e ventilação natural.

Como consequência da preocupação sobre a sustentabilidade criaram-se certificados para avaliar esses requisitos. Que levam em conta todas as preocupações sobre esse assunto.

\section{Certificação na Construção Civil}

Em 1990 surgiu na construção civil o conceito da construção sustentável, assim, surgiu o BREEAM (Building Research Establishment Environmental Assessment Method), voltada principalmente para o Reino Unido, a qual a edificação recebe um selo verde.

O BREEAM define padrões para as melhores práticas de sustentabilidade em construções, e se tornou o mais abrangente e reconhecido pelas medidas de desempenho ambiental. Incentivam arquitetos, clientes e outros a pensarem na baixa emissão de carbono, minimizando a demanda de energia de um edifício antes de considerar a eficiência energética e tecnologias de redução de carbono. Esse tipo de certificação reconhece o desempenho a partir de parâmetros estabelecidos, para avaliar especificação do edifício, projeto, construção e uso, incluindo aspectos relacionados à energia, uso de água, ambiente interno (saúde e bemestar), poluição, transporte, materiais, desperdícios, ecologia e processos de gestão.

O BREEAM usa um sistema de pontuação clara e simples, tem uma influência positiva sobre a concepção, construção e gestão de edifícios, define e mantém uma norma técnica robusta, com garantia de qualidade rigoroso. Sobre os parâmetros que utilizam, pode-se citar:

1. Energia: eficiência energética do edifício levando em consideração a emissão de carbono.

2. Gerenciamento: política de gerenciamento das obras.

3. Saúde e bem-estar: conforto ambiental interno, como acústica, luminosidade e qualidade do ar.

4. Transporte: localização dos transportes e emissão de carbono.

5. Água: eficiência no uso/consumo da água.

6. Materiais: impactos causados pelos materiais usados na edificação, ciclo de vida dos mesmos e baixa emissão de carbono. 
Elza Cristina Santos; Alessandra Pantaleão Dirscherl

7. Resíduos: eficiência nos recursos na construção e gerenciamento de descartes.

8. Uso da terra: pegada ecológica de terrenos.

9. Poluição: nível e controle de poluição do ar exterior e da água.

10. Ecologia: valor ecológico e preservação do terreno.

A pontuação da certificação varia de $30 \%$ até $85 \%$, a soma dos créditos da edificação a caracteriza como:

Pass- $30 \%$

Good $-45 \%$

Very good $-55 \%$

Excellent $-70 \%$

Outstanding $-85 \%$

No Brasil, somente em 2007 foi criado o GBCBrasil (Green Building Council Brasil), que avalia as edificações brasileiras através da referência do LEED (Leadership in Energy and Environmental Design), que é o sistema internacional de certificação ambiental.

O LEED é utilizado em 143 países, com o objetivo de qualificar as obras no requisito de sustentabilidade. Além das mudanças ambientais, que diz a respeito do uso racional de recursos naturais, uso de materiais de baixo impacto ambiental, redução no consumo de água e energia; há também melhorias sociais: conscientização da população, bem-estar dos usuários, e econômicos: diminuição de custos operacionais, menor obsolescência das edificações, valorizações de imóveis.

A certificação varia entre 40 e 110 pontos, sendo este considerado o nível platina. Ao que deve ser analisado, o LEED possui 7 dimensões, dentre as quais possuem práticas que são obrigatórias, são elas:

1. Espaço sustentável: estratégias que minimizam impactos no ecossistema durante a implantação do edifício, abordando questões urbanas, como ilhas de calor.

2. Eficiência do uso da água: proposta de uso racional da água, como reuso e redução de consumo da água potável. 
3. Energia e atmosfera: promove eficiência energética, através de simulações energéticas, medições e utilização de equipamentos e sistemas eficientes.

4. Materiais e recursos: utilizar materiais de baixo impacto ambiental, reciclados e que reduz a geração de resíduos, descartar de modo consciente de modo a diminuir os resíduos da construção civil nos aterros sanitários.

5. Qualidade ambiental interna: promove a qualidade interna dos ambientes, no que diz respeito a escolher materiais de baixa emissão de compostos orgânicos voláteis, controlabilidade do sistema, conforto térmico, priorização dos espaços no que diz respeito a luz natural.

6. Inovação e processos: buscar conhecimento sobre Green Buildings, medidas projetuais que não estão nas categorias do LEED. É nessa categoria que há pontos de desempenho exemplar.

7. Créditos de prioridade regional: incentiva os créditos definidos de cada país, de acordo com as diferenças sociais, econômicas e ambientais do país. Quatro pontos são disponíveis nessa categoria.

As classificações do LEED são: LEED (40 pontos), LEED Silver (50 pontos), LEED Gold (60 pontos) e LEED Platinum (80 pontos).

No ano de 2008 foi criado o selo de certificação ambiental AQUA (Alta Qualidade Ambiental) que se baseia no conceito de sustentabilidade para emitir a certificação, levando em conta aspectos ambientais, sociais e econômicos. Foi a primeira que levou em conta os aspectos no Brasil para o desenvolvimento de um selo de qualificação ambiental em edifícios, foi criada e gerida por professores do Departamento de Engenharia de Produção na Escola Politécnica da Universidade de São Paulo (USP).

O AQUA foi criado a partir do selo francês HQE (Haute Qualité Environmentale). Manuel Carlos Martins, o coordenador executivo do AQUA explicou a escolha do selo francês como referência: “os franceses estão bem avançados em termos de certificação para construções sustentáveis, então pegamos o processo amadurecido. Além disso, a França tem uma história de parceria com a Poli e se dispôs a abrir todo o seu trabalho para que 
Elza Cristina Santos; Alessandra Pantaleão Dirscherl

pudéssemos aproveitá-lo. A Europa é mais abrangente e profunda em questões ambientais e nossa identificação foi maior com eles".

O selo do AQUA possui quatro critérios para a avaliação ambiental e técnica das obras arquitetônicas (PRADO, 2008), resumindo-se:

1. Eco-construção: relaciona o edifício com o entorno, escolha integrada de produtos, sistemas e processos construtivos e canteiro de obras com baixo impacto ambiental.

2. Gestão: de energia, água, resíduos de uso e operação do edifício e manutenção para ter permanência do desempenho ambiental.

3. Conforto: acústico, visual, olfativo e higrotérmico.

4. Saúde: do ar e da água, e qualidade sanitária dos ambientes.

No Brasil, quem trabalha com a certificação de Sistemas de Qualidade é a Fundação Vanzolini desde 1990, é ela quem emite o selo AQUA (PRADO, 2008). O AQUA é importante para que a certificação seja feita com referenciais ambientais, econômicas e sociais brasileiras, o que outros selos como o LEED não propõe, pois muitos critérios não condizem com a realidade brasileira.

Está sendo exigido na construção civil o LEED ou AQUA, porém o cumprimento com suas exigências não significa que o projeto será sustentável. A mudança para obras mais sustentáveis está ligado também às mudanças culturais e projetuais.

Abaixo está representado em um mapa os principais processos de certificação no mundo. 
Elza Cristina Santos; Alessandra Pantaleão Dirscherl

Figura 1: Selos sustentáveis no mundo

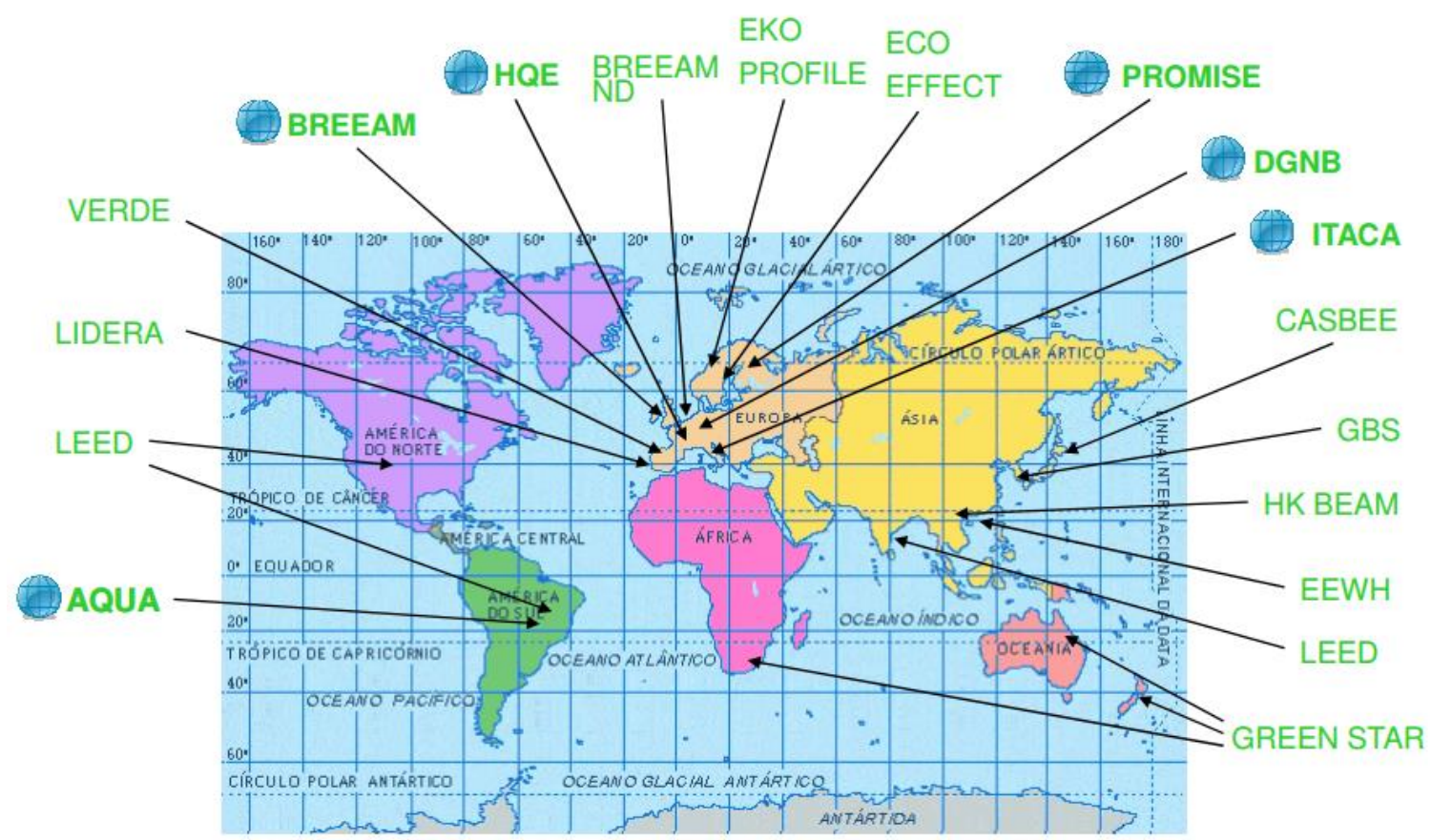

Fonte: Fundação Vanzolini

\section{O Questionário e a Entrevista}

A princípio, o objetivo da aplicação do questionário (Anexo A) é analisar o posicionamento das construtoras diante dos agentes imobiliários, dos elementos que norteiam o processo projetual, das questões que envolvem a sustentabilidade e o que pensam sobre o processo de certificação em edifícios de apartamentos. Os questionários foram aplicados em construtoras das cidades de Uberlândia - MG e Ribeirão Preto- SP, pois também é objetivo, a comparação dos resultados, em quais aspectos cidades médias se assemelham e se diferenciam.

Para aplicar o questionário foram procuradas nove construtoras / incorporadoras de Uberlândia e doze de Ribeirão Preto, sendo que somente duas de Uberlândia responderam e duas de Ribeirão Preto retornaram o questionário, respondidos de forma incompleta.

No questionário, duas questões importantes sobre o mercado imobiliário foram abordadas, a primeira é a respeito dos agentes imobiliários, que são os proprietários, as imobiliárias, as construtoras, incorporadores e clientes. Outro ponto abordado foi sobre a 
Elza Cristina Santos; Alessandra Pantaleão Dirscherl

“consumização" das habitações, termo que remete aos imóveis que são comprados visando o lucro e não sua real finalidade de habitação.

Com relação ao processo de projeto, são vários os aspectos abordados, tais como: o que influencia no programa de necessidades escolhido; qual a importância atribuída ao arquiteto, coordenador e gerente de projetos; a tipificação, que consiste no uso de projetos iguais empregados em locais diferentes do país; se os dirigentes da empresa são notificados sobre os projetos e se há um banco de dados para alimentar decisões dos projetos, isso é de extrema importância para a prevenção de futuros erros.

Sobre os projetos, é necessário também analisar se há revisão, o que evita erros, se há interface entre os projetos (arquitetônico, estrutural, elétrico, entre outros), para que assim já possam ser observados os erros a tempo de consertá-los e evitar prejuízos e atrasos durante a fase de construção. Sendo assim, é importante documentar as soluções adotadas para que possa ser futuramente utilizada.

A respeito da sustentabilidade, os aspectos abordados no questionário foram: a orientação e tamanho de aberturas do edifício, uma vez que diminui custos com energia elétrica, usada para iluminação e ar-condicionado e o emprego de materiais que condizem com o desempenho térmico do local, fundamental para amenizar o clima interno da edificação.

Também foi questionada a existência de estratégias de reuso de água e economia de energia. Foram feitas questões com foco nos materiais, pois como o maior número de entulho vem da construção civil é importante utilizar materiais reciclados e também que possam ser reciclados. O emprego de materiais que condizem com o desempenho térmico do local é fundamental para amenizar o clima interno da edificação. É interessante também utilizar materiais com maior durabilidade, diminuindo reformas, o que gera lixo.

Por fim, foi importante saber o que as construtoras pensam a respeito da certificação na construção civil, se são realmente eficazes ou somente um artifício publicitário com interesse apenas de venda. Foi abordado também, questões a respeito de pesquisas pós-ocupacionais, se são realizadas, porque isso afeta a qualidade de melhoria de projetos futuros. 
Elza Cristina Santos; Alessandra Pantaleão Dirscherl

\section{Comparações dos Resultados entre as Construtoras/Incorporadores de Uberlândia e Ribeirão Preto}

É interessante comparar os resultados obtidos pelo questionário, podendo observar quais são as semelhanças e diferenças das cidades médias no que diz respeito ao pensamento das construtoras sobre mercado imobiliário, processo de projeto, sustentabilidade e certificação.

A respeito do mercado imobiliário, foi interessante perceber que uma das duas construtoras de cada cidade deu igual relevância a todos os agentes imobiliários, mostrando assim, que cada um cumpre com o seu papel dependendo do outro e que um não existe sem o outro. Uma semelhança entre três das quatro foi que focaram no cliente quando questionados sobre o papel dos agentes, defendendo a ideia que eles são os principais compradores e influenciam as decisões projetuais.

Sobre a tendência para se construir apartamentos hoje, nota-se muita disparidade. Isso ocorre em razão de cada construtora focar em uma linha de concepção espacial que acaba atraindo clientes que se interessam pelo tipo de projeto que oferecem. Assim, há diferença de tendências tanto nas cidades diferentes como entre as construtoras de uma mesma cidade.

No quesito "consumização", uma construtora de Uberlândia explicou que as questões sociais são problemáticas, e que os problemas já podem ser percebidos na cidade em razão da classe social mais baixa morar em locais longes de serviços, comércios e do próprio local de trabalho, mas não possuem outra opção, uma vez que há especulação imobiliária em lugares que possuem serviços e comércios. Outra construtora de Ribeirão Preto avaliou a “consumização" pelo fato de que o aumento de demanda é bom para o mercado imobiliário.

Outro fator de semelhança entre duas das construtoras, sendo uma de cada cidade, é que quando questionados sobre as pesquisas que fazem de mercado, escolheram as mesmas opções: identificar demandas, características e necessidades dos potenciais clientes e tipologias com demanda potencial. Isso mostra que cidades de médio porte, que possuem número de habitantes muito aproximados tendem a realizar o mesmo tipo de pesquisas, às vezes até conseguindo alcançar melhor o desejo dos clientes em vista de outras construtoras.

Tanto em Uberlândia quanto em Ribeirão a maioria das construtoras fazem seus projetos de acordo com a necessidade do público alvo, que são os possíveis moradores das áreas que irão construir. Foi possível observar que todas as construtoras deram importância ao 
arquiteto, dando a eles o papel de projetar para que as obras sejam bem executadas, sendo então possível observar cada vez mais a importância e valorização dada a esse profissional.

Para a maioria das construtoras o coordenador é importante para o andamento do projeto, sendo essencial na gestão de projetos, porém somente uma delas, de Uberlândia, possui esse tipo de profissional. É necessário, que além de admitir sua importância, contratem o coordenador e o gerente de projetos, muitas empresas vêem isso como um gasto extra, porém não é, pois eles fazem com que o andamento do projeto seja mais rápido pela eficiência da execução e controlando gastos.

A respeito do conhecimento do processo projetual pelos dirigentes das empresas, uma de cada cidade faz relatórios de atividades para enviar aos mesmos. Das outras duas, também uma de cada cidade, faz reuniões. Sendo assim é possível perceber que as duas práticas são presentes nas duas cidades.

As empresas também tiveram a mesma opinião sobre a tipificação das habitações verticalizadas, elas não são adequadas, pois cada lugar merece um estudo diferente de acordo com suas necessidades, porém deve-se admitir que é uma solução barata e rápida. O que também foi uma opinião em comum entre todas as construtoras foi o fato de que os clientes escolhem morar em apartamentos pela segurança. Sendo assim, percebe-se que cidades de médio porte, com índices altos de violência tendem a se verticalizar, pois edifícios de apartamentos geram uma sensação de segurança para os moradores. Outro motivo igual entre duas empresas de cidades diferentes foi a facilidade de limpeza e manutenção.

Sobre pesquisas para tomar decisões no processo de projeto, duas das empresas, uma em Uberlândia e uma em Ribeirão Preto realizam pesquisas. Assim, também é um fator em comum, pois há empresas que tem a necessidade de fazer pesquisas, mas outras não.

Uma diferença entre as empresas de Uberlândia e Ribeirão Preto é que na primeira, para a escolha das áreas envolvidas para a formulação inicial do projeto, todos os itens foram escolhidos. Na segunda, as construtoras escolheram apenas alguns dos itens, sendo diferentes para cada empresa.

Em todas as construtoras o arquiteto e o calculista estão presentes na concepção do projeto, mas foi possível observar que em Uberlândia há mais profissionais envolvidos além desses citados, a exemplo do projetista de instalações, também citado em uma das empresas de Ribeirão Preto. Assim, pode-se perceber que para se desenvolver qualquer projeto em uma construtora esses três profissionais estão sempre presentes. Todas as construtoras também 
Elza Cristina Santos; Alessandra Pantaleão Dirscherl

possuem arquitetos parceiros, já percebendo uma tendência em contratar um arquiteto terceirizado.

Para a maioria das empresas o coordenador possui a mesma função. Isso mostra que, mesmo quando não possuem coordenador de projetos, sabem a função desse profissional. Dentre as quatro empresas, três revisam e alteram os projetos quando necessários. Todas as quatro realizam a análise das interfaces dos projetos e documentam soluções, isso é um ponto positivo porque mostra que em cidades de médio porte se realizam projetos buscando uma qualidade futura.

Foi possível observar também que todas as construtoras analisam as propostas dos projetistas levando em consideração os preços e a organização interna e recursos das empresas.

A respeito da sustentabilidade, somente uma construtora de Ribeirão Preto o respondeu, sendo assim, somente a resposta dessa empresa será comparada com as de Uberlândia.

Todas as três construtoras que responderam sobre sustentabilidade no questionário preocupam com a implantação, o posicionamento das aberturas a fim de favorecer ventilação e também projetam as janelas ultrapassando a determinação do código de obras. A respeito da utilização de proteção nas fachadas mais críticas, a construtora de Ribeirão Preto e uma de Uberlândia utilizam quando necessário. Assim, pode-se perceber que há uma mínima preocupação em amenizar a insolação nas fachadas mais críticas. Em todas elas também a área verde faz parte do processo projetual.

A respeito do reuso de água, uma empresa de Uberlândia utiliza desse processo e a empresa de Ribeirão também. Para economizar energia, nenhuma construtora de Uberlândia possui recursos, já a de Ribeirão disponibiliza infraestrutura para a instalação de aquecedores solares. Para alternativas para economia de energia normalmente são utilizadas placas solares, pois a instalação de placas fotovoltaicas possui um custo muito elevado.

A maioria das empresas busca construir com materiais que possuem inércia térmica compatível com o clima da cidade, o que reduz muitas vezes usos de alternativas que gastam energia elétrica para manter o conforto dos ambientes internos dos edifícios. Todas as construtoras buscam empregar materiais isentos de compostos orgânicos voláteis. Também fazem uso de materiais com vida longa útil, o que evita reparações no futuro e diminui o lixo de construções civis. A empresa de Ribeirão Preto e uma de Uberlândia não fazem uso de materiais reciclados, mas em todas as empresas os materiais podem ser reciclados. Assim, 
Elza Cristina Santos; Alessandra Pantaleão Dirscherl

mesmo sem fazer uso de materiais reciclados, é interessante que podem ser reciclados quando descartados. Os edifícios, quando em fase de construção, contam com a coleta seletiva em todas as construtoras.

A construtora de Ribeirão Preto e uma de Uberlândia pensam nas soluções que serão empregadas no edifício na fase de concepção do projeto, e a outra empresa de Uberlândia pensa na fase de construção. É importante que as soluções sejam pensadas na fase de processo de projeto, para que não haja problemas na fase de construção.

Sobre certificação da construção civil, as duas construtoras de Ribeirão Preto não responderam ao questionário, não sendo possível comparar os resultados com as construtoras de Uberlândia.

\section{Considerações Finais}

Foi possível notar, a partir das entrevistas, que as cidades médias possuem uma mesma referência no que diz respeito à construção civil. Havendo mais semelhanças do que diferenças no modo de como pensam a respeito dos aspectos de processo de projeto, e também da sustentabilidade.

Foi notório, por exemplo, que cada construtora possui um tipo de cliente diferente, e que os projetos são destinados a esses clientes. Sendo assim, também se percebe uma tendência, que é o foco para determinados tipos de projetos, sendo muito raro construtoras e incorporadoras que desenvolvem diferentes tipos de projetos. Isso pode ser um ponto positivo para que as empresas melhorem o projeto do qual desenvolvem, pois um projeto retroalimenta o próximo, fazendo com que os projetos melhorem cada vez mais.

É importante na formação de um arquiteto saber avaliar uma edificação a fím de melhorar um projeto futuro, corrigir o que foi feito de forma equívoca nos projetos anteriores e sanar os erros, a fim de que os projetos de habitação cada vez mais cheguem próximos do seu objetivo e também, melhorar outros projetos de forma a serem mais sustentáveis. A observação dos ambientes construídos, avaliações pós-ocupacionais, montagem de um banco de dados e o desenvolvimento de um bom projeto faz com que o arquiteto perceba melhor os ambientes físicos, e também como os moradores se relacionam com o lugar que moram. 
Elza Cristina Santos; Alessandra Pantaleão Dirscherl

\section{Referências}

ADESSE, Eliane; SALGADO, M. S. Importância do coordenador do projeto na gestão da construção: a visão do empreendedor. Seminário Internacional NUTAU, 2006.

BARROS, Raquel R. M. P. HABITAÇÃO COLETIVA: a inclusão de conceitos humanizados no processo de projeto. Annablume. São Paulo. 2011.

CERTIFICAÇÃO DE EDIFÍCIOS SUSTENTÁVEIS. Breeam. Disponível em: <http://www.vivianecunha.com.br/portugues/images/breeam_pdf_print.pdf >. Acesso em: 6 abr. 2014.

CERTIFICAÇÃO LEED. Disponível em: <http://www.gbcbrasil.org.br/?p=certificacao $>$. Acesso em: 17 fev. 2014.

ELALI, G. A.; VELOSO, M. Avaliação pós-ocupação e processo de concepção projetual em arquitetura: uma relação a ser melhor compreendida. SEMINÁRIO INTERNACIONAL NUTAU, 2006, São Paulo. Anais, São Paulo: 2006.

GESTÃO DE PROJETOS. Líder de projeto, coordenador de projeto, gerente de projeto,... esclarecendo cada função! Disponível em <http://www.verxconsulting.com.br/br/gestao-deprojetos/28-lider-de-projeto-coordenador-de-projeto-gerente-de-projeto-esclarecendo-cadafuncao>. Acesso em: 10 set. 2013

LAMBERTS, R.; DUTRA, L.; RUTTKAY, P. Eficiência energética na arquitetura. São Paulo: PW, 1997.

LIMA, F. M. A. Programa arquitetônico: ferramenta de sustentabilidade. V Encontro Nacional e III Encontro Latino-Americano sobre edificações e Comunidades Sustentáveis. Recife. 2009.

MARQUES, F. M.; SALGADO, M. S. Padrões de sustentabilidade aplicados ao processo de projeto. VII Workshop Brasileiro de Gestão do Processo de Projetos na Construção de Edifícios, Curitiba, PR, 2007.

MELHADO, S. B; ADESSE; et al. A Gestão de projetos de edificações e o escopo de serviços para coordenação de projetos. Paper, 2006, s.p.

MOEHLECKE, Juliana. Uma contribuição para o desenvolvimento de assentamentos humanos mais sustentáveis: identificação de padrões urbanos relacionados aos princípios de sustentabilidade. Universidade Federal do Rio Grande do Sul - Escola de Engenharia. Porto Alegre. 2010.

MOTTA, S. R. F.; AGUILAR, M. T. P. Sustentabilidade e processos de projeto de edificações. Gestão \& Tecnologia de Projetos, v. 4, n. 1, 2009.

PINTO, A. D. S. O papel do programa de necessidades no processo de projeto arquitetônico. Revista on-line IPOG. Especialize. 2013. 
PRADO, Thays. AQUA: primeiro referencial técnico brasileiro para construções sustentáveis. Disponível em:

<http://planetasustentavel.abril.com.br/noticia/desenvolvimento/conteudo_275506.shtml >. Acesso em: 26 fev. 2014.

RAMIRES, J. C. de L. A Verticalização do Espaço Urbano de Uberlândia: Uma análise da produção e consumo da habitação. 1998. Tese (Doutorado em Geografia) - Universidade de São Paulo / Faculdade de Filosofia, Letras e Ciências Humanas, São Paulo.

REIS, A. T. L.; LAY, M. C. D. Avaliação da qualidade de projetos - uma abordagem perceptiva e cognitiva. Ambientes construído. Porto Alegre, v. 6, n. 3, p.21-34. 2006.

RESIDÊNCIAS: etiquetas para quem consome menos. AMBIENTE ENERGIA, 04 dez. 2010. Disponível em: <http://www.ambienteenergia.com.br/index.php/2010/12/residenciasetiquetas-para-quem-consome-menos/7672>. Acesso em: 12 out. 2013.

SALGADO, M. S. Produção arquitetônica e interdisciplinaridade: uma discussão sobre o processo de projeto e a ISO 9001/2000. São Paulo, SP. 2004. 11 p. CONFERÊNCIA LATINO-AMERICANA DE CONSTRUÇÃO SUSTENTÁVEL: ENCONTRO NACIONAL DE TECNOLOGIA DO AMBIENTE CONSTRUÍDO, 10², 2004, São Paulo, SP.

SANTANA, Karla Almeida. O processo de projeto em construtoras e incorporadoras no distrito federal: um exercício de avaliação com foco na concepção e definição do produto. 2009. Dissertação de mestrado - Universidade de Brasília. Faculdade de Arquitetura e Urbanismo - FAU, Brasília. 2009

SILVA, V. G. Avaliação da sustentabilidade de edifícios de escritórios brasileiros: diretrizes e base metodológica. 2003. Tese (Doutorado em Engenharia da Construção Civil) Escola Politécnica, Universidade de São Paulo, São Paulo, 2003.

SILVA, V. G. Indicadores de sustentabilidade de edifícios: estado da arte e desafios para desenvolvimento no Brasil. Ambiente Construído. Porto Alegre, v. 7, n. 1, p. 47-66. 2006.

SOUZA, A. L. R.; MELHADO, S. B. A importância do projeto para produção no incremento da qualidade do produto edifício. Congresso Latino-Americano, Tecnologia e gestão na produção de edifícios: soluções para o terceiro milênio - Escola Politécnica de Universidade de São Paulo. PCC-USP. São Paulo. 1998.

VILLA, S. B. Apartamento Metropolitano: habitações e modos de vida na cidade de São Paulo. 2002. 220f. Dissertação (Mestrado em Arquitetura e Urbanismo) - Universidade de São Paulo / Escola de Engenharia de São Carlos/ Faculdade de Arquitetura e Urbanismo, São Carlos.

Morar em Apartamentos: a produção dos espaços privados e semi-privados nos apartamentos ofertados pelo mercado imobiliário no século XXI - São Paulo e Ribeirão Preto. Critérios para Avaliação Pós-Ocupação. 2008. 360f. Tese (Doutorado em Arquitetura e Urbanismo) - Universidade de São Paulo / Faculdade de Arquitetura e Urbanismo, São Paulo. 
Elza Cristina Santos; Alessandra Pantaleão Dirscherl

Avaliando a Habitação: Relações entre qualidade, projeto e avaliação pós-ocupação em apartamentos. In: ANTAC - Associação Nacional de Tecnologia do Ámbiente Construído, 2005, Porto Alegre. Artigo Técnico.

VILLA, S. B.; CAETANO, F. G. A NBR 15.575:2013 e a qualidade dos apartamentos ofertados pelo mercado imobiliário. $13^{\mathrm{a}}$ Conferência Internacional da LARES. São Paulo, 2013.

VILLA, S. B.; ORNSTEIN, S. W. Projetar apartamentos com vistas à qualidade arquitetônica a partir dos resultados da avaliação pós-ocupação (APO). GESTÃO \& TECNOLOGIA DE PROJETOS, v. 5, p. 35/115-60, 2010.

WHAT IS BREEAM? Disponível em: <http://www.breeam.org/about.jsp?id=66>. Acesso em: 03 fev. 2014.

ZAMBRANO, L. M. A. Integração dos princípios de sustentabilidade ao projeto de arquitetura. 2008. Tese (Doutorado em Ciências em Arquitetura) - Universidade Federal do Rio de Janeiro, Rio de Janeiro, 2008. 


\section{Anexo A - Questionário efetuado nas entrevistas}

\section{$\underline{\text { Entrevista aos incorporadores e construtoras }}$}

Como aluna de graduação da Universidade Federal de Uberlândia, regular no Programa Institucional de Bolsas de Iniciação Científica PIBIC/UFU, estou desenvolvendo, juntamente com a professora orientadora Elza Cristina Santos, uma pesquisa sobre o processo de projeto em habitações verticais em cidades médias, especificamente Uberlândia e Ribeirão Preto, que está inserida numa investigação maior, intitulada "[HABITAÇÃO VERTICAL] Avaliação da qualidade espacial e ambiental de edifícios de apartamentos em cidades médias" coordenada pela professora Simone Villa.

Nesse sentido, importa saber qual é o papel do coordenador e do gerente de projetos, como também quais são os principais aspectos necessários para melhorar a qualidade dos projetos, e torná-los sustentáveis.

A realização do questionário foi fundamentada principalmente na dissertação de mestrado da Karla Almeida Santana, "O processo de projeto em construtoras e incorporadoras no Distrito Federal", e também na dissertação de pós-graduação da Juliana Moehlecke, "Uma contribuição para o desenvolvimento de assentamentos humanos mais sustentáveis: identificação de padrões urbanos relacionados ao princípios de sustentabilidade".

A pesquisa deverá ser reenviada para o email: alepantadir@ hotmail.com

Atenciosamente,

Alessandra Pantaleão Dirscherl

Aluna de graduação da Faculdade de Arquitetura, Urbanismo e Design - UFU.

Entrevista

Empresa:

Local:

Data:

\section{Mercado imobiliário}

a) Quais são os principais agentes (proprietários, imobiliária, construtora, incorporador, clientes) do mercado imobiliário hoje?

b) Como você avalia o grau de importância de cada um dos diferentes agentes na viabilidade ou sucesso do empreendimento?

c) Qual o papel de cada agente do mercado nas decisões projetuais dos empreendimentos?

d) Atualmente que tendências você poderia apontar em relação aos projetos e à construção de edifícios de apartamentos? 
e) O que você pensa sobre a "consumização" da habitação cada vez mais expressa pelo mercado imobiliário atual?

f) A empresa realiza ou contrata pesquisas de mercado para identificar:
( ) demandas
( ) lançamentos de outras empresas e seus preços de venda
( ) faixas de renda em determinada região
( ) características e necessidades dos potenciais clientes
( ) capacidade do financiamento
( ) oportunidade de negócios
( ) tipologias com demanda potencial.

\section{Projeto}

a) Com relação ao programa de necessidades, quais os critérios que mais influenciam/determinam o produto a ser lançado no mercado imobiliário? Existe algum procedimento documentado para isso?

b) Como são identificadas as demandas? Há pesquisas sérias ou apenas intuição/ experiência?

c) Qual é o papel do arquiteto e urbanista no processo de definição e elaboração do projeto de edifícios de apartamentos hoje?

d) O que a empresa pensa a respeito da função do coordenador de projeto?

e) Os dirigentes das empresas têm conhecimento do processo de projeto? De que forma?

f) Existe um gerente e um coordenador de projetos?

g) Você acredita que a tipificação ${ }^{2}$ é a melhor e a mais adequada solução para habitação verticalizada?

h) Quais seriam, na sua ótica, os principais fatores que influem na decisão do cliente em morar em apartamentos?

i) No processo de projeto ha algum tipo de pesquisa (banco de dados) que alimenta as decisões? Indicar qual.

\footnotetext{
${ }^{1}$ Consumização: a residência é vista como um bem de consumo visando o lucro, e não tem uma relação de lar. Usar o método de habitar como modo de adquirir renda.

${ }^{2}$ Tipificação: padronização das habitações (plantas e materiais) em projetos mesmo quando construídos em locais diversos.
} 
Quais são as áreas envolvidas na formulação inicial do produto?
( ) Ténica/projetos
( ) Imobiliárias
( ) Obras/produção
( ) Arquiteto
( ) Comercial
( ) Administrativo/financeiro
( ) Incorporação
( ) Diretoria geral
( ) Marketing

Quais projetistas estão envolvidos na concepção do projeto?
( ) Arquiteto
( ) Decorador
( ) Calculista
( ) Outro
( ) Projetista de instalações

Como é feita a escolha do arquiteto:
( ) Concursos
( ) Indicação
( ) Já possui arquitetos parceiros
( ) Conhecimentos específicos de algum arquiteto

Existem critérios formais de qualidade para seleção de projetistas?

( ) $\operatorname{Sim}($ ) Não

O responsável pela coordenação dos projetos:

( ) Monitora o processo a fim de tomar ações corretivas em tempo hábil

( ) Acompanha e atualiza o cronograma financeiro de desembolso de projeto

A empresa:

( ) define e documenta as etapas e prazos necessários para o desenvolvimento dos projetos considerando as demandas dos projetistas

( ) define e documenta as aprovações de projetos necessárias

( ) define soluções para pontos específicos do produto.

Há controle de revisão e alterações dos projetos?

( ) Sim ( ) Não

É feita a identificação e análise critica das interfaces técnicas dos projetos?

( ) Sim ( ) Não

São definidas e documentadas soluções para as interfaces técnicas dos projetos?

( ) Sim ( ) Não

Ao analisar as propostas técnicas dos projetistas, são utilizados critérios de qualificação para a análise das propostas técnicas como:
( ) atuação no mercado
( ) preço
( ) consulta a outros clientes do projetista
( ) análise da organização interna e dos recursos da empresa
( ) análise dos currículos do responsável técnico e da equipe interna. 
Elza Cristina Santos; Alessandra Pantaleão Dirscherl

\section{Sustentabilidade}

Considerando os impactos das edificações e das cidades sobre o meio ambienteno ramo da arquitetura, o interesse e a preocupação com o projeto e construção de tipologias sustentáveis é cada vez maior. Por isso, muitos projetos são desenvolvidos utilizando materiais favoráveis de baixo impacto ambiental, evitando-se também o desperdício e utilizando técnicas que ajudem na economia de energia elétrica e água. Sobre esse panorama, gostaríamos de saber:

a) Há alguma preocupação na forma de como as edificações são implantadas (em termos de orientação solar)?

b) As janelas são dimensionadas para a entrada de luz natural ou respeitam apenas as determinações dos códigos de obras?

c) As aberturas são posicionadas em locais estratégicos, para favorecer a ventilação natural?

d) São utilizadas proteções solares (como brises) em fachadas críticas?

e) As áreas permeáveis dos projetos respeitam os códigos de obras ou as áreas verdes fazem parte do processo projetual? De que forma?

f) Os conjuntos habitacionais possuem algum tipo de recurso para reutilização de água?

g) São aplicados mecanismos que ajudam a reduzir o consumo de água? Quais?

h) E quanto ao consumo de energia? Existe alguma estratégia para reduzir a demanda energética dos empreendimentos?

i) Quais são os principais materiais de construção utilizados?

j) Existe preocupação em escolher materiais que tenham inércia térmica compatível com o clima de Uberlândia/ Ribeirão Preto?

k) Há emprego de materiais isentos de compostos orgânicos voláteis?

1) Os materiais de construção utilizados possuem uma vida útil longa?

m) Existe uso de material reciclado?

n) Os materiais podem ser recicláveis quando descartados (em razão, por exemplo, de reformas ou demolição)?

o) Os edifícios contam com coleta seletiva de resíduos? 
p) De maneira geral, quais são as soluções empregadas para atender às questões de sustentabilidade?

q) Essas soluções são pensadas durante a fase de projeto ou de construção?

\section{Certificação da qualidade habitacional}

a) Qual é o papel hoje dos prêmios de certificação de qualidade na área da construção civil?

b) Os prêmios são "jogadas" publicitárias ou há realmente uma metodologia para a escolha dos premiados?

c) Os métodos de avaliação da satisfação utilizados pelos prêmios são realmente eficazes?

d) Qual é o papel da APO (avaliação pós-ocupação) hoje nas empresas que compõem o mercado imobiliário?

e) Esta empresa utiliza pesquisas de avaliação pós ocupação para pautar as decisões de projeto? De que forma empresa investe em inovação? Indique os tipos e ações. 

SP

Elza Cristina Santos; Alessandra Pantaleão Dirscherl

\section{Referências do questionário}

ADESSE, Eliane; SALGADO, M. S. Importância do coordenador do projeto na gestão da construção: a visão do empreendedor. Seminário Internacional NUTAU, 2006.

MOEHLECKE, Juliana. Uma contribuição para o desenvolvimento de assentamentos humanos mais sustentáveis: identificação de padrões urbanos relacionados aos princípios de sustentabilidade. Universidade Federal do Rio Grande do Sul - Escola de Engenharia. Porto Alegre. 2010.

SANTANA, Karla Almeida. O processo de projeto em construtoras e incorporadoras no distrito federal: um exercício de avaliação com foco na concepção e definição do produto. 2009. Dissertação de mestrado - Universidade de Brasília. Faculdade de Arquitetura e Urbanismo - FAU, Brasília. 2009 